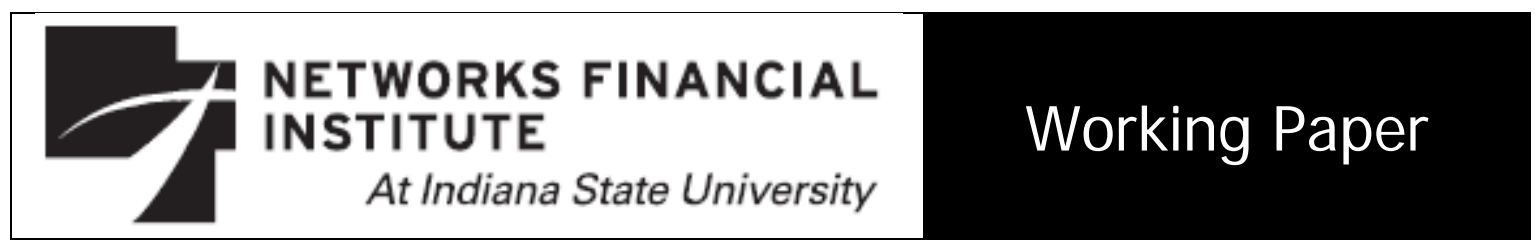

2010-WP-07

December 2010

\title{
Urbanization, Old-Age Security, Saving and Fertility in Developing Economies
}

Joel M. Guttman

Abstract: This paper develops a two-sector overlapping generations (OLG) model of the co-evolution of urbanization, saving, and fertility in developing economies. Children are viewed as a means of old-age support, particularly in the rural sector, as well as a good valued for its own sake. It is shown that, under plausible parameter assumptions, a very mild rate of technological change is sufficient to yield large increases in the saving rate and in the level of urbanization, and large decreases in the fertility rate over time, which accords well with the experience of the Asian Tigers.

About the Author: J oel M. Guttman is a Senior Fellow at Networks Financial Institute. Guttman is currently serving as an associate professor in the department of economics in Bar-Ilan University. He has also served as a visiting professor at the University of Chicago, Brown University and the Helsinki School of Economics. His research areas include evolution of trust and cooperation, economic growth and conflict (internal and external), public economics, applied game theory, and defense economics. He has published numerous articles in scholarly journals including American Economic Review, Journal of Political Economy, Journal of Public Economics, and Economic Journal. He received his Ph.D. in economics from the University of Chicago.

Keywords: Old-age security hypothesis, two-sector growth models, urbanization, endogenous fertility.

J EL Classification: 014, J13.

The views expressed are those of the individual author and do not necessarily reflect official positions of Networks Financial Institute. Please address questions regarding content to J oel M. Guttman at guttmanj@neto.net.il. Any errors or omissions are the responsibility of the author.

NFI working papers and other publications are available on NFI's website (www.networksfinancialinstitute.org). Click "Thought Leadership" and then "Publications/Papers." 


\section{Introduction}

The "economic miracle" in East Asia has been studied by a large and growing literature, motivated by the hope that the lessons to be learned from this miracle can be applied in other developing countries. One of the most striking aspects of this miracle has been the huge increase in the savings rate in these countries, enabling high rates of economic growth according to the neoclassical growth model. In Taiwan, for example, the savings rate increased from about 10 percent in 1955 to more than 50 percent in 1990. In South Korea, the corresponding increase was from about 5 percent in 1955 to approximately 35 percent in 1990, and similarly for the other Asian Tigers. Over the same time period, fertility dropped sharply in these countries. The average total fertility rate (TFR) in East Asia declined from more than five children in 1955 to approximately two children in 1990.

The traditional explanation of the increase in the savings rate, deriving from the life-cycle (LC) model of Modigliani and Brumberg (1954), is that the decrease in the number of children per family lowered the dependency rate, thus increasing households' income net of the costs of raising children, and inducing an increase in the savings rate. Empirical evidence, however, has not consistently supported this explanation. ${ }^{1}$ Indeed, while in South Korea, Taiwan, and Malaysia the increase in the savings rate approximately coincided with the decrease in the population share of individuals aged less than 16 (thus supporting the LC hypothesis), in Thailand the savings rate began its sharp rise about 15 years before the decrease in the less-than-16 dependency rate, and in India the dependency rate has stayed approximately constant despite the increase in the savings rate.

The present paper endogenizes urbanization, fertility and savings decisions. The paper shows that both the increase in the savings rate and the decline in the fertility rate (which increase growth in per capita income) partially can be explained by rural-to-urban migration, which in turn is a consequence of growth of per capita income, via Engel's Law. ${ }^{2}$ Thus ur-

\footnotetext{
${ }^{1}$ See Hammer (1986) and Schultz (2005) for surveys of the literature.

${ }^{2}$ I am indebted to my late teacher, D. Gale Johnson, for pointing out the role of Engel's
} 
banization is caused by growth and also can cause growth. Urbanization is transforming a traditional familial system in which children are raised in order to obtain old-age support, to a modern system with weak family ties and monetized support for the elderly through individual savings. ${ }^{3}$

The literature on urbanization and growth has emphasized the role of cities in the accumulation of human capital and the stimulation of technological change. These effects were recognized already by Marshall (1890), who pointed out that in cities "the mysteries of the trade become no mysteries; but are, as it were, in the air." The recent literature begins with the pioneering contributions of Jacobs $(1969,1984)$ and continues through the models of Glomm (1992), Glaeser (1999), Zhang (2002), Lucas (2004), and Sato and Yamamoto (2005), among others. The formal structure of the present model is closer, however, to the work of Shin (1995), who emphasizes the role of Engel's Law in explaining urbanization as a consequence of growth. ${ }^{4}$ Nevertheless, the present model incorporates the basic insight of the literature by endogenizing technological change, making it an increasing function of the level of urbanization of the economy.

Section 2 of this paper presents a simple two-sector overlapping generations (OLG) growth model in which children are raised for old-age support as well as for the direct utility they provide. Section 3 presents simulations of the model. Section 4 concludes.

\section{Model}

In the model, individuals live three time periods: childhood, active adulthood and old age. When they are active adults, individuals raise children, support their elderly parents, and save income for their old age. When old, they are supported by their children and by their saved income. Before developing the model in detail, however, I first address a question that has

Law in causing urbanization.

${ }^{3}$ For a related model in which endogenous family ties are linked to endogenous labor regulations which lead to static inefficiencies (as opposed to dynamic inefficiencies, in the present model), see Alesina et al. (2010).

${ }^{4}$ Glomm (1992) also incorporates Engel's Law in his model of growth and urbanization. 
been raised by others in the literature on children as sources of old age support [see, e.g., Shubik (1981), Becker (1988), Cigno (1993), Stark (1995)], but (in my view) has not been adequately answered by most of the literature: Why do rational children support their parents when the parents have reached old age?

\subsection{Understanding children's support for elderly parents}

Given that parents cannot sign a formal contract with their children to ensure their children's support in their old age, the question arises as to what enforces any implicit agreement that may exist regarding such old age support. One can distinguish between two approaches in the literature:

Theories following the first approach introduce "non-standard" preferences. One such approach (see, e.g., Becker, 1988) is simply to assume that children are altruistic toward their parents, just as economists (Barro, 1974; Becker, 1974, 1981, 1991; and others) recognize that parents are altruistic toward their children. Becker $(1993,1996)$ has also proposed that parents may be able to influence the preferences of their children so as to make them want to support their parents. A complementary approach, that of Cox and Stark (1996), refers to a "demonstration effect:" when children observe their parents supporting their grandparents, the children develop preferences to support their parents. While some empirical support has been found for this effect (Mitrut and Wolff, 2009), the demonstration effect theory has several logical difficulties (see Jellal and Wolff, 2002; Bergstrom and Stark, 1993).

The second approach posits that there is a self-enforcing, implicit intergenerational contract, which Cigno (1993) has called a "family constitution." Such a contract specifies that if one's parents supported their parents, then one is obligated to support his or her parents. It can be shown that this implicit contract is self-enforcing in an infinite series of generations, if agents give sufficient weight to their future income (when they are old). The underlying idea is essentially an application of the Folk Theorem of infinitely repeated games. Each agent faces a "trigger strategy" played by his or her children, since (according to the implicit contract) if the parent does not 
support his parents, then the children will not support him.

As noted above (see also Ehrlich and Lui, 1991, p. 1039), the "family constitution" theory assumes that the intergenerational game is infinitely repeated. This assumption would be reasonable if the economic environment were static, and the return on alternative investments was expected to be eternally lower than the return on investment in one's children as a source of old-age support. Once the process of economic development begins, however, this expectation would be irrational, as will be clear from the analysis in the remainder of this section. A rational parent would expect that eventually the return on alternative investments might rise above the return on investment in one's children. Given this rational expectation, some future generation would be expected to opt out of the family constitution. This, in turn, would lead to an unraveling of the family constitution back to the generation whose expectations of future returns have changed. Suppose, for example, that the generation that decides to opt out is generation $T$. Then generation $T-1$, in its economically active (working) stage, would not want to support its parents, expecting that their children will not support them in any case. But then generation $T-2$ would also not support its parents, and so forth, back to the first generation whose expectations have adapted to a changing economic environment.

In static economic environments, the family constitution approach has the advantage of making only standard assumptions about preferences, and therefore being capable of explaining why the intrafamilial old-age support system is relied upon by the vast majority of parents in traditional societies. ${ }^{5}$ In contrast, the explanatory power of the first group of theories is open to question. But, as noted above, the family constitution theory is a priori very weak in economies undergoing change. The infinite-horizon assumption is simply untenable in such economies.

In Guttman (2001a, 2001b) I proposed an alternative explanation of children's support of their elderly parents, which synthesizes aspects of the

\footnotetext{
${ }^{5}$ For example, even in 1986 a survey of elderly Javanese found that 50 percent of male respondents and 70 percent of female respondents reported relying on children or grandchildren for "at least some income." [Hugo (1992), cited by Frankenberg et al. (2002).]
} 
previous two sets of theories. Like the first group of theories that posit nonopportunistic preferences, parents are assumed to invest time and effort to inculcate preferences for reciprocity in their children. But unlike the other theories of the first category, the efficacy of such parental "moral education" is not assumed to extend beyond a minority of the individuals in society. In other words, a minority of agents are assumed to be reciprocators due to parental training.

The remaining, opportunistic agents, who simply maximize their material payoff, nevertheless mimic the behavior of the reciprocators in order to maintain reputations for being reciprocators - reputations that have pecuniary value in the local marketplace. The same preference for reciprocity which induces a reciprocator to repay his parents' investment when his parents are old, also causes him to fulfill the terms of market transactions even when he is not forced to do so by the legal system (which is assumed to be largely absent in rural areas in less developed countries). If a reciprocator is selling a good, for example, he will not want to violate the terms of his agreement with his buyers. Assuming that a sufficiently large percentage of the population are true reciprocators, the remaining, opportunistic types are induced, in equilibrium, to build reputations for being reciprocators, in order to have the trust of future trading partners in market transactions. The opportunists are induced both to honor trust in their market transactions and to support their parents up to (but not including) the last stages of their careers, in order not to ruin their reputations. Thus the approach of Guttman (2001a, 2001b) is fundamentally game-theoretic, like the "family constitution" theory, but with the crucial difference that it is applicable to a finitely repeated game, as in Kreps, et al. (1982). Therefore the model does not presume a static economic environment, unlike the family constitution theory.

A critical assumption of the model of Guttman (2001a, 2001b) is that agents have good information of the past behavior of their peers, an assumption that is realistic in a small, tightly knit rural community, but not in a large, anonymous city. Without this assumption, opportunistic agents could abstain from supporting their parents and cheat their trading partners 
without being punished by a loss of reputation. Thus the model of Guttman (2001a, 2001b) predicts that the probability that a randomly drawn agent will support his or her parents in their old age is a decreasing function of the size of the community in which the agent is located. This provides us with a negative relationship between the reliability of the family old-age support system and urbanization, a relationship which is not predicted either by the altruism approach or by the family constitution approach.

Guttman (2001a) indeed provides evidence that in rural areas of Italy and Slovenia, survey respondents' care for their parents (measured by the frequency of visits to their elderly mothers) is lower for older respondentsimplying that the respondent's time horizon in his reputational game is relatively short - while a corresponding decline is not statistically significant in urban areas. This result suggests that most agents' motive for supporting their parents is reputational, and therefore is effective only in rural areas. Additionally, on the average for all ages, visits to one's mother are significantly less frequent when the local population is relatively large, i.e., in urban areas. This result, which is corroborated by Bian, et al. (1998) and by Zimmer and Kwong (2003) for China, further supports the model of Guttman (2001a, 2001b).

\subsection{Assumptions of the model}

In the present model [unlike the model of Guttman (2001a, 2001b)] parents do not invest resources in order to inculcate preferences for reciprocity in their children. Instead (and like standard reputation models) it is assumed that a certain, exogenous proportion of the population, $\rho \in(0,1)$, consists of reciprocator types. ${ }^{6}$ For simplicity, it is assumed that the type of the children is statistically independent of the type of the parents.

\footnotetext{
${ }^{6}$ For evolutionary models endogenizing $\rho$ without assuming parental investment in inculcating preferences for reciprocity, see Guttman $(2000,2003)$ as well as the work surveyed by Sethi and Somanathan (2003). There is a great deal of experimental evidence that (some) agents indeed have preferences for reciprocity, beginning with pioneering work of Güth, et al. (1982) on the ultimatum game and Berg, et al. (1995) on the trust game.
} 
Agents are assumed to live three time periods, childhood (period 0), active adulthood (period 1) and old age (period 2). Children are purely passive and therefore play no role in the model. In each period, agents receive utility from consumption $c$ and the number of children $n_{t}{ }^{7}$ Thus the lifetime utility of an agent (starting in adulthood) is

$$
U_{t}=U\left(c_{1 t}, c_{2 t}, n_{t}\right)
$$

where the subscripts denote the time period $t$ that the agent enters adulthood (which indicates the agent's cohort) and the time period in the agent's life, 1 or 2 . This utility function will be specified in greater detail below.

It is assumed that the agent's decision whether to support his or her parents is made before the remaining decisions regarding the arguments of $U$. As argued in Guttman (2001a, 2001b), the agent supports his or her parents if either (a) the agent is a reciprocator type (which has probability $\rho$ ), or (b) the agent is located in a rural area and therefore supports his or her parents for reputational reasons. ${ }^{8}$ As in Guttman (2001a, 2001b) as well as in most of the other models cited above, the agent's decision whether to support his or her parents is treated as a binary decision: either the agent supports his or her parents at a socially mandated level $\bar{g}$, or he or she does not support them at all.

The socially mandated level of children's support of their parents, $\bar{g}$, is assumed to be an increasing, concave function of the per capita income of the parents when they were economically active. ${ }^{9}$ In other words, a rich community will expect the children to support their parents at a higher

\footnotetext{
${ }^{7}$ For simplicity, the parents are assumed to be unable to invest in the "quality" of their children.

${ }^{8}$ As shown in Guttman (2001a, 2001b), in the latter case an opportunistic agent will not support his or her parents in the last stages of his or her "career." As in Kreps, et al. (1982), the number of these endgame stages is independent of the overall number of stages of the agent's career. The number of stages in the agent's career is taken to be very large, allowing us to ignore the implied reduction in the support that the average agent provides to his or her parents.

${ }^{9}$ The use of the parents' per capita income as the basis of the standard of support simplifies the analysis, by avoiding the need for the agent to form expectations of his children's income in order to decide how to allocate his own wealth between consumption in period 1 and consumption in period 2 of his lifetime.
} 
level than a poor community, but the expected level of support - given that it is supposed to cover basic needs - does not increase linearly with the per capita income of the community. ${ }^{10}$ In particular, it is assumed that

$$
\bar{g}_{t}=g_{0} w_{t-1}^{1 / 2}
$$

where $g_{0}>0$ is an exogenous parameter and $w_{t-1}$ is wage income of generation $t-1$. Thus the total support received by parents of generation $t$ from their children (who are part of generation $t+1$ ), if all of the latter support their parents, is $g_{0} w_{t}^{1 / 2} n_{t} \cdot{ }^{11}$

To simplify the analysis, it is assumed that the adult agent contracts the care for his or her children to a nursemaid, who provides this care at the price of $\eta w_{t}$ per child where $\eta \in(0,1)$. It is assumed that the number of nursemaids is very small relative to the number of other economically active adults, so that we may ignore their consumption and saving decisions in the following analysis.

The agent has one unit of time, which he or she devotes entirely to working (the agent has no preference for leisure). Thus the agent maximizes $U_{t}$ subject to two constraints. The first constraint is the first-period budget constraint

$$
w_{t}=c_{1 t}+S_{t}+g_{0} w_{t-1}^{1 / 2}+\eta w_{t} n_{t}
$$

where $w_{t}$ is the wage rate at time $t, n_{t}$ is the number of children the agent raises, and $S_{t}$ is savings. This constraint is written on the assumption that the agent supports his or her parents. If this assumption does not hold, the $g_{0} w_{t-1}^{1 / 2}$ term will be absent from the equation.

The agent's second-period budget constraint is

$$
S_{t} R_{t}+\pi n_{t} g_{0} w_{t}^{1 / 2}=c_{2 t},
$$

\footnotetext{
${ }^{10}$ This assumption is supported by evidence for Malaysia presented in Lillard and Willis (1997, Table 7), who find that the income elasticity of money support from women to their parents is approximately 0.34 , while the corresponding elasticity for men is 0.25 for permanent earnings, and 0.15 for current earnings.

${ }^{11}$ While we have been using the terminology "parents" in the plural, the model treats the parents as a single agent, for simplicity.
} 
where the $R_{t}$ is 1 plus the rate of return on savings, and $\pi$ is the probability that each child will support his or her parents, which takes one of two values: 1 for children residing in a rural area and $\rho \in(0,1)$ for children residing in an urban area.

The proportion $\phi_{t} \in(0,1)$ of the total adult population $N_{t}$ resides in urban areas, and the proportion $1-\phi_{t}$ resides in rural areas. The variable $\phi_{t}$ is endogenous. All economically active adults residing in urban areas produce a manufactured good, widgets, denoted $m$, while all those residing in rural areas produce food, denoted $f$. The sectors producing these two goods are both assumed to be perfectly competitive.

It is assumed that both goods are produced by two factors, labor and capital. In order to make the model tractable and to focus on the issues of central interest, it is assumed that the relative intensity of the two factors are the same in the two sectors. A constant returns to scale (CRS) Cobb-Douglas production function is assumed in both sectors. Thus the production function of food is

$$
Q_{f t}=A_{f t} L_{f t}^{\beta} K_{f t}^{1-\beta}
$$

where $A_{f t}>0$ is a technology parameter, $\beta \in(0,1), L_{f t}$ is the amount of labor and $K_{f t}$ is the amount of capital in the rural sector. Since each adult agent in the rural sector is assumed to work in the production of food, and each worker supplies one unit of labor time, we have

$$
Q_{f t}=A_{f t}\left[\left(1-\phi_{t}\right) N_{t}\right]^{\beta} K_{f t}^{1-\beta}
$$

The production function of widgets is

$$
Q_{m t}=A_{m t} L_{m t}^{\beta} K_{m t}^{1-\beta}
$$

where $A_{m t}>0$ is a technology parameter. Again, there are $\phi_{t} N_{t}$ workers in the urban sector, and each supplies one unit of labor time, so that

$$
Q_{m t}=A_{m t}\left(\phi_{t} N_{t}\right)^{\beta} K_{m t}^{1-\beta}
$$


As indicated in the Introduction, the model incorporates Engel's Law, which states that the income elasticity of demand for food is less than unity. Accordingly, the utility function is assumed to be non-homothetic. For simplicity, the utility function is (the logarithm of) a Stone-Geary utility function $^{12}$

$$
U_{t}=\ln \left(f_{1 t}-\bar{f}\right)+\ln m_{1 t}+\delta\left[\ln \left(f_{2 t}-\bar{f}\right)+\ln m_{2 t}\right]+\alpha \ln \left(n_{t}-1\right)
$$

where $\alpha \in(0,1)$ is a preference parameter, $\delta \in(0,1)$ is the discount parameter and $\bar{f}>0$ is a minimum "subsistence" level of food consumption. Note that the agent also has a minimum "acceptable" number of children, namely 1. Since we are assuming, for simplicity of exposition, that the agent raises children without a mate, one child is the minimum required for replacement of the current population.

The price of food is normalized to unity. The price of widgets is $p_{m t}$. Thus the value of consumption which appears in (1) and (2) is

$$
c_{1, t}=f_{1 t}+p_{m t} m_{1 t}
$$

and

$$
c_{2, t}=f_{2 t}+p_{m, t+1} m_{2 t} .
$$

(Note that the subscript $t+1$ in $p_{m, t+1}$ refers to the price of widgets at time $t+1$ which is period 2 of the cohort dated $t$.)

Capital is accumulated by diverting widgets from current consumption to production in the next time period. Over this time interval, the widgets "mature" (e.g., seedlings mature into trees), yielding a marginal return whose present value at time $t$ is ${ }^{13}$

$$
\left(\frac{\partial Q_{f, t+1}}{\partial K_{f, t+1}}\right) \frac{1}{p_{m t} R_{t}}=\left(\frac{\partial Q_{m, t+1}}{\partial K_{m, t+1}}\right) \frac{1}{R_{t}}
$$

\footnotetext{
${ }^{12}$ See Stone (1954).

${ }^{13}$ The fraction $1 / p_{m t}$ appears on the left-hand side because the price of a widget is $p_{m t}$ while the price of a unit of food is unity. On the right-hand side, which is the marginal return to capital in the urban sector, $p_{m t}$ appears in both the numerator and denominator and therefore cancels out.
} 
where $R_{t}$ is 1 plus the interest rate. After this one-period return, the invested widget completely depreciates. Thus

$$
K_{t+1}=\frac{S_{t}}{p_{m t}}
$$

where $K_{t+1}$ is the economy-wide stock of capital at time $t+1$ and $S_{t}$ is the level of saving at time $t$.

$R_{t}$ is bounded below by 1 , since if the interest rate were negative (implying $R_{t}<1$ ), agents would simply store widgets for consumption or sale in the next time period, rather than investing them in widgets-as-capital. For simplicity, it is assumed that the cost of storage is zero.

\subsection{Analysis of the model}

\subsubsection{The consumer's problem}

To solve the consumer's problem we form the Lagrangian, using (1), (2), (5), and (6),

$$
\begin{aligned}
\mathcal{L}_{t}= & \ln \left(f_{1 t}-\bar{f}\right)+\ln m_{1 t}+\delta\left[\ln \left(f_{2 t}-\bar{f}\right)+\ln m_{2 t}\right]+\alpha \ln \left(n_{t}-1\right) \\
& +\lambda_{t}\left[w_{t}-f_{1 t}-p_{m t} m_{1 t}-S_{t}-g_{0} w_{t-1}^{1 / 2}-\eta w_{t} n_{t}\right] \\
& +\mu_{t}\left[S_{t} R_{t}+\pi g_{0} w_{t}^{1 / 2} n_{t}-f_{2 t}-p_{m, t+1} m_{2 t}\right]
\end{aligned}
$$

where $\lambda_{t}$ and $\mu_{t}$ are Lagrangian multipliers. (Again, if the agent does not support his or her parents, the $g_{0} w_{t-1}^{1 / 2}$ term will be absent.) We obtain the following first-order conditions:

$$
\begin{gathered}
\frac{\partial \mathcal{L}_{t}}{\partial f_{1 t}}=\frac{1}{f_{1 t}-\bar{f}}-\lambda_{t}=0 \\
\frac{\partial \mathcal{L}_{t}}{\partial m_{1 t}}=\frac{1}{m_{1 t}}-\lambda_{t} p_{m t}=0 \\
\frac{\partial \mathcal{L}_{t}}{\partial f_{2 t}}=\frac{\delta}{f_{2 t}-\bar{f}}-\mu_{t}=0 \\
\frac{\partial \mathcal{L}_{t}}{\partial m_{2 t}}=\frac{\delta}{m_{2 t}}-\mu_{t} p_{m, t+1}=0
\end{gathered}
$$




$$
\begin{gathered}
\frac{\partial \mathcal{L}_{t}}{\partial n_{t}}=\frac{\alpha}{n_{t}-1}-\lambda_{t} \eta w_{t}+\mu_{t} \pi g_{0} w_{t}^{1 / 2}=0 \\
\frac{\partial \mathcal{L}_{t}}{\partial S_{t}}=-\lambda_{t}+\mu_{t} R_{t}(1-\theta)=0 \\
\frac{\partial \mathcal{L}_{t}}{\partial \lambda_{t}}=w_{t}-f_{1 t}-p_{m t} m_{1 t}-S_{t}-g_{0} w_{t-1}^{1 / 2} n_{t-1}^{-1 / 2}-\eta w_{t} n_{t}=0
\end{gathered}
$$

and

$$
\frac{\partial \mathcal{L}_{t}}{\partial \mu_{t}}=S_{t} R_{t}+\pi g_{0} w_{t}^{1 / 2} n_{t}-f_{2 t}-p_{m, t+1} m_{2 t}=0 .
$$

Combining (8) and (9), we obtain

$$
m_{1 t}^{*}=\frac{f_{1 t}^{*}-\bar{f}}{p_{m t}}
$$

where the asterisk denotes the optimal value. Similarly, using (10) and (11), we have

$$
m_{2 t}^{*}=\frac{f_{2 t}^{*}-\bar{f}}{p_{m, t+1}} .
$$

Equation (13) implies

$$
R_{t}=\frac{\lambda_{t}}{\mu_{t}}
$$

Combining (8), (10) and (18), we obtain

$$
f_{2 t}^{*}-\bar{f}=\left(f_{1 t}^{*}-\bar{f}\right) \delta R_{t}
$$

and, by combining (17) and (19),

$$
m_{2 t}^{*}=\frac{\left(f_{1 t}^{*}-\bar{f}\right) \delta R_{t}}{p_{m, t+1}} .
$$

\subsubsection{Endogenous fertility}

We now turn to the agent's demand for children. Using (12) and (18), we obtain

$$
n_{f t}^{*}=1+\frac{\alpha}{\eta \lambda_{t} w_{t}-\mu_{t} g_{0} \sqrt{w_{t}}}
$$


for farm families (denoted by $f$ in the subscript on the left-hand side), where the probability that the children will support their parents is unity. ${ }^{14}$ Dividing the numerator and denominator of the fraction on the right-hand side by $\mu_{t}$ and substituting (10), (18) and (19), we obtain

$$
n_{f t}^{*}=1+\frac{\alpha\left(f_{f, 1 t}-\bar{f}\right) R_{t}}{\eta R_{t} w_{t}-g_{0} \sqrt{w_{t}}}
$$

Similarly, for urban families,

$$
n_{u t}^{*}=1+\frac{\alpha\left(f_{u, 1 t}-\bar{f}\right) R_{t}}{\eta R_{t} w_{t}-\rho g_{0} \sqrt{w_{t}}}
$$

where the probability that the children will support their parents is $\rho<1$. $^{15}$ (To be more precise, $n_{u t}^{*}$ will differ between opportunistic and reciprocatortype agents, since their optimal food consumption will differ, because of their differing decisions regarding whether to support their parents.) Thus, for a given level of period 1 food consumption, rural families have more children than urban families, since raising children is a better investment in rural areas. These equations also make clear that, in this model, an increased return on alternative investments, $R_{t}$, as well as an increased wage rate $w_{t}$, reduce the demand for children, by raising their opportunity cost.

\subsubsection{Conditions of general equilibrium}

Labor is assumed to be perfectly mobile between the two sectors. Therefore, in equilibrium, the wage rate will be equal in the two sectors. Since all markets are competitive, the value of the marginal product of labor will be

\footnotetext{
${ }^{14}$ It is assumed, for simplicity, that rural parents expect that their children will stay in the same community with probability 1 . When there is migration but it is not too rapid, this assumption will still hold approximately. Relaxing this assumption would greatly complicate the analysis without providing additional insights.

${ }^{15}$ Note that the denominator of (21) and of (22) must be positive, since the net "price" of a child, which is the difference between the period 1 cost and the period 2 investment return, must be positive in order for the agent to choose an interior solution regarding $n_{t}$.
} 
equal to the wage in both sectors:

$$
w_{t}=\beta A_{f t}\left(\frac{K_{f t}}{L_{f t}}\right)^{1-\beta}=\beta p_{m t} A_{m t}\left(\frac{K_{m t}}{L_{m t}}\right)^{1-\beta}
$$

Equality of the marginal rate of technical substitution between capital and labor in the two sectors implies

$$
\frac{K_{f t}}{L_{f t}}=\frac{K_{m t}}{L_{m t}}=\frac{K_{t}}{L_{t}}
$$

in equilibrium. Combining (23) and (24), we obtain

$$
\widehat{p}_{m t}=\frac{A_{f t}}{A_{m t}}
$$

and

$$
\widehat{w}_{t}=\beta A_{f t}\left(\frac{K_{t}}{L_{t}}\right)^{1-\beta}=\beta A_{f t} k_{t}^{1-\beta}
$$

where

$$
k_{t} \equiv \frac{K_{t}}{L_{t}}=\frac{K_{t}}{N_{t}}
$$

since $N_{t}=L_{t}$ by assumption, and the superscript hat denotes the equilibrium value. From (25), we obtain the following result: If there is no technological change, or if technological change in the two sectors proceeds at the same rate, then the price of widgets will be constant over time and will equal $A_{f t} / A_{m t}$.

\subsubsection{Equilibrium saving and consumption}

Consider an adult agent in the rural sector. Substituting (16), (21), (26) and (27) into (1), we obtain

$$
\beta A_{f t} k_{t}^{1-\beta}=2 f_{1 t, f}^{*}-\bar{f}+S_{t f}+g_{0} w_{t-1}^{1 / 2}+\eta w_{t}\left[1+\frac{\alpha\left(f_{1 t}^{*}-\bar{f}\right) R_{t}}{\eta R_{t} w_{t}-g_{0} \sqrt{w_{t}}}\right]
$$

for the agent's equilibrium first-period budget constraint (the subscript $f$ on the right-hand side denotes "farm" which corresponds to its meaning on the 
left-hand side, "food"). The corresponding constraint for an opportunistic urban agent (who does not support his or her parents, as argued in Section $2.1)$ is

$$
\beta A_{f t} k_{t}^{1-\beta}=2 f_{1 t, u o}^{*}-\bar{f}+S_{t, u o}+\eta w_{t}\left[1+\frac{\alpha\left(f_{1 t, u o}^{*}-\bar{f}\right) R_{t}}{\eta R_{t} w_{t}-\rho g_{0} \sqrt{w_{t}}}\right],
$$

where the subscript $u o$ denotes "urban-opportunistic" and the subscript $u$ denotes "urban," as in (22). Finally, the corresponding constraint for a reciprocator-type urban agent (who does support his or her parents) is

$$
\beta A_{f t} k_{t}^{1-\beta}=2 f_{1 t, u r}^{*}-\bar{f}+S_{t, u r}+g_{0} w_{t-1}^{1 / 2}+\eta w_{t}\left[1+\frac{\alpha\left(f_{1 t, u r}^{*}-\bar{f}\right) R_{t}}{\eta R_{t} w_{t}-g_{0} \sqrt{w_{t}}}\right],
$$

where the subscript ur denotes "urban-reciprocator."

Substituting (19), (20), and (21) into (2) and simplifying, the secondperiod budget constraint for a rural adult agent is

$$
S_{t f} R_{t}+g_{0} w_{t}^{1 / 2}\left[1+\frac{\alpha\left(f_{1 t}^{*}-\bar{f}\right) R_{t}}{\eta R_{t} w_{t}-g_{0} \sqrt{w_{t}}}\right]=2\left(f_{1 t, f}^{*}-\bar{f}\right) \delta R_{t}+\bar{f} .
$$

Using (22) instead of (21), the corresponding constraint for an opportunistic urban agent is

$$
S_{t, u o} R_{t}+\rho g_{0} w_{t}^{1 / 2}\left[1+\frac{\alpha\left(f_{1 t, u o}^{*}-\bar{f}\right) R_{t}}{\eta R_{t} w_{t}-\rho g_{0} \sqrt{w_{t}}}\right]=2\left(f_{1 t, u o}^{*}-\bar{f}\right) \delta R_{t}+\bar{f},
$$

and, for a reciprocator-type urban agent,

$$
S_{t, u r} R_{t}+\rho g_{0} w_{t}^{1 / 2}\left[1+\frac{\alpha\left(f_{1 t, u r}^{*}-\bar{f}\right) R_{t}}{\eta R_{t} w_{t}-\rho g_{0} \sqrt{w_{t}}}\right]=2\left(f_{1 t, u r}^{*}-\bar{f}\right) \delta R_{t}+\bar{f} .
$$

Solving (28) and (29) simultaneously, we obtain the optimal saving and first-period food consumption of a rural adult. The resulting expressions are 
very messy and unenlightening. For example, the agent's optimal saving is

$$
\begin{aligned}
S_{t f}^{*}= & w_{t}\left\{1-\eta\left[1-\frac{\alpha \bar{f} R_{t}}{\eta R_{t} w_{t}-g_{0} \sqrt{w_{t}}}\right]\right\} \\
& -\left\{2+\frac{\eta w_{t} \alpha R_{t}}{\eta R_{t} w_{t}-g_{0} \sqrt{w_{t}}}\right\}\left\{\frac{2 S_{t f} R_{t}+g_{0} w_{t}^{1 / 2}+\bar{f}\left(2 \delta R_{t}-1\right)}{R_{t}\left[2 \delta-\frac{g_{0} \alpha w_{t}^{1 / 2}}{\eta R_{t} w_{t}-g_{0} \sqrt{w_{t}}}\right]}+\bar{f}\right\} \\
& +\bar{f}-g_{0} w_{t-1}^{1 / 2} .
\end{aligned}
$$

Similar expressions can be derived for the urban agents by solving $\left(28^{\prime}\right)$ and $\left(29^{\prime}\right)$ simultaneously (for opportunistic agents), and $\left(28^{\prime \prime}\right)$ and $\left(29^{\prime \prime}\right)$ simultaneously (for opportunistic agents). Using (16), (17), and (19), the equilibrium consumption of food in period 2 of the agent's life and his or her consumption of widgets in both periods can be derived from these expressions, for each agent type.

Once the equilibrium consumption and saving decisions are derived for the three types of agent (urban-opportunistic, urban-reciprocator, and rural), it is straightforward to compute the equilibrium $\phi_{t}$, the proportion of the population living in urban areas. Recall that savings are invested to purchase widgets which serve as investment goods as well as consumption goods, and that widgets are produced only in cities, while food is produced only in rural areas. In equilibrium, the demand for widgets is

$$
\begin{aligned}
Q_{m t}^{d} \equiv & \left(1-\phi_{t}\right)\left(m_{1 t, f}^{*}+\frac{S_{t f}^{*}}{p_{m t}}\right) N_{t} \\
& +\phi_{t}\left[\rho\left(m_{1 t, u r}^{*}+\frac{S_{t, u r}^{*}}{p_{m t}}\right)+(1-\rho)\left(m_{1 t, u o}^{*}+\frac{S_{t, u o}^{*}}{p_{m t}}\right)\right] N_{t}+ \\
& \left\{\left(1-\phi_{t-1}\right) m_{2, t-1, f}^{*}+\phi_{t-1}\left[\rho m_{2, t-1, u r}^{*}+(1-\rho) m_{2, t-1, u o}^{*}\right]\right\} N_{t-1},
\end{aligned}
$$

where the first two lines express the demand for widgets of generation $t$, and the third line is the corresponding demand of generation $t-1$ who are currently in period 2 of their lives. Similarly, in equilibrium, the demand 
for food is

$$
\begin{aligned}
Q_{f t}^{d} \equiv & \left\{\left(1-\phi_{t}\right) f_{1 t, f}^{*}+\phi_{t-1}\left[\rho f_{1 t, u r}^{*}+(1-\rho) f_{1 t, u o}^{*}\right]\right\} N_{t}+ \\
& \left\{\left(1-\phi_{t-1}\right) f_{2, t-1, f}^{*}+\phi_{t-1}\left[\rho f_{2, t-1, u r}^{*}+(1-\rho) f_{2, t-1, u o}^{*}\right]\right\} N_{t-1} .
\end{aligned}
$$

Given our assumption that the production functions of the two sectors are CRS and are identical except for their technology coefficients $A_{f t}$ and $A_{m t}$, we have

$$
\frac{Q_{m t}^{d}}{Q_{f t}^{d}}=\frac{\phi_{t} A_{m t}}{\left(1-\phi_{t}\right) A_{f t}} .
$$

Solving (30) for $\phi_{t}$, we obtain the equilibrium distribution of the population (and the capital stock) between the two sectors. ${ }^{16}$

\section{Simulations}

In order to run simulations, one must address the issue of agents' formation of expectations regarding (a) the period-2 price of widgets $p_{m, t+1}$, and (b) the period- 2 marginal productivity of capital, which determines the period-1 interest rate $R_{t}$, as in equation (6), where both sides of that equation equal 1 . The problem of specifying $p_{m, t+1}$ is avoided by making technological change progress at the same rate in the two sectors, which keeps $p_{m}$ constant, as noted above at the end of Section 2.3.3. Regarding the specification of the interest rate, an iterative procedure was used to approximate agents' rational expectation of $\partial Q_{m, t+1} / \partial K_{m, t+1}$. This procedure begins with generation $t$ 's "inherited" capital stock $K_{t}$ and population size $N_{t}$. Using the economy-wide capital-labor ratio $K_{t} / N_{t}$, one obtains a first approximation to $\partial Q_{m, t+1} / \partial K_{m, t+1}$ [noting that the economy-wide capital-labor ratio will equal, in equilibrium, the same ratio in both sectors, as stated by (24)].

\footnotetext{
${ }^{16}$ The demand of children for widgets and food is neglected in these calculations. Taking their demand explicitly into account would require modeling the parents' decision as to how much food and widgets should be supplied to their children. Instead, it is implicitly assumed that the children's demand is distributed between widgets and food in a ratio that is roughly similar to the economy-wide average demand ratio.
} 
Given this first approximation, $R_{t}$ is set equal to $\partial Q_{m t} / \partial K_{m t}$. The first approximation of $R_{t}$ is then used to derive equilibrium saving $S_{t}$ and fertility. Using $S_{t}$ and projected population growth, an estimate of the next-period marginal productivity of capital $\partial Q_{m, t+1} / \partial K_{m, t+1}$ can be derived. $R_{t}$ is accordingly revised, by taking the average of the estimated $\partial Q_{m, t+1} / \partial K_{m, t+1}$ and of the first approximation of $R_{t}{ }^{17}$ The new approximation of $R_{t}$ is then used again to derive equilibrium saving and fertility, and the procedure repeats itself until the difference between the revised estimate of $R_{t}$ and that of the previous iteration is within a preset level of tolerance, $0.1 .^{18}$

Without technological change, the model economy rapidly converges to a steady state, with constant wages, consumption, saving rates, and ratio of urban to rural population. In order to investigate the implications of the model for economic growth and urbanization, a very mild rate of endogenous technological change (reaching a maximum rate of 2.5 percent per generation in both sectors) is assumed. The rate of technological change is made a function of the level of urbanization. ${ }^{19}$ Specifically, if we denote the rate of technological change by $\theta_{t}$, it is assumed that $\theta_{t}=0.025 \phi_{t-1}$. Thus, if the economy had no urban sector $(\phi=0)$, there would be no technological change. In order to highlight the effect of technological change on the economy, such change is introduced only at $t=20$. Thus the steady state without technological change is shown clearly in the simulations. In order to allow the steady state to be reached, the horizontal axis in the figures begins at $t=5$.

Figure 1 shows the time path of urbanization under the following parameter assumptions: $A_{f 0}=20, A_{m 0}=10, \eta=0.15, \rho=0.1, \alpha=0.9$, $\delta=0.9, g_{0}=0.7, N_{0}=30, K_{0}=25, \beta=0.75, \bar{f}=3$. Aside from $\beta$, for which there are established estimates, these parameter assumptions are

\footnotetext{
${ }^{17}$ Taking this average was found to speed convergence.

${ }^{18}$ In the simulations reported here, the maximum number of iterations is 1,000 , and nevertheless in the second and third generations the procedure did not converge to this level of tolerance. In all other generations, however, convergence to within this tolerance level was achieved.

${ }^{19}$ The results are actually very similar if an exogenous rate of technological change of 2 percent per generation is assumed.
} 


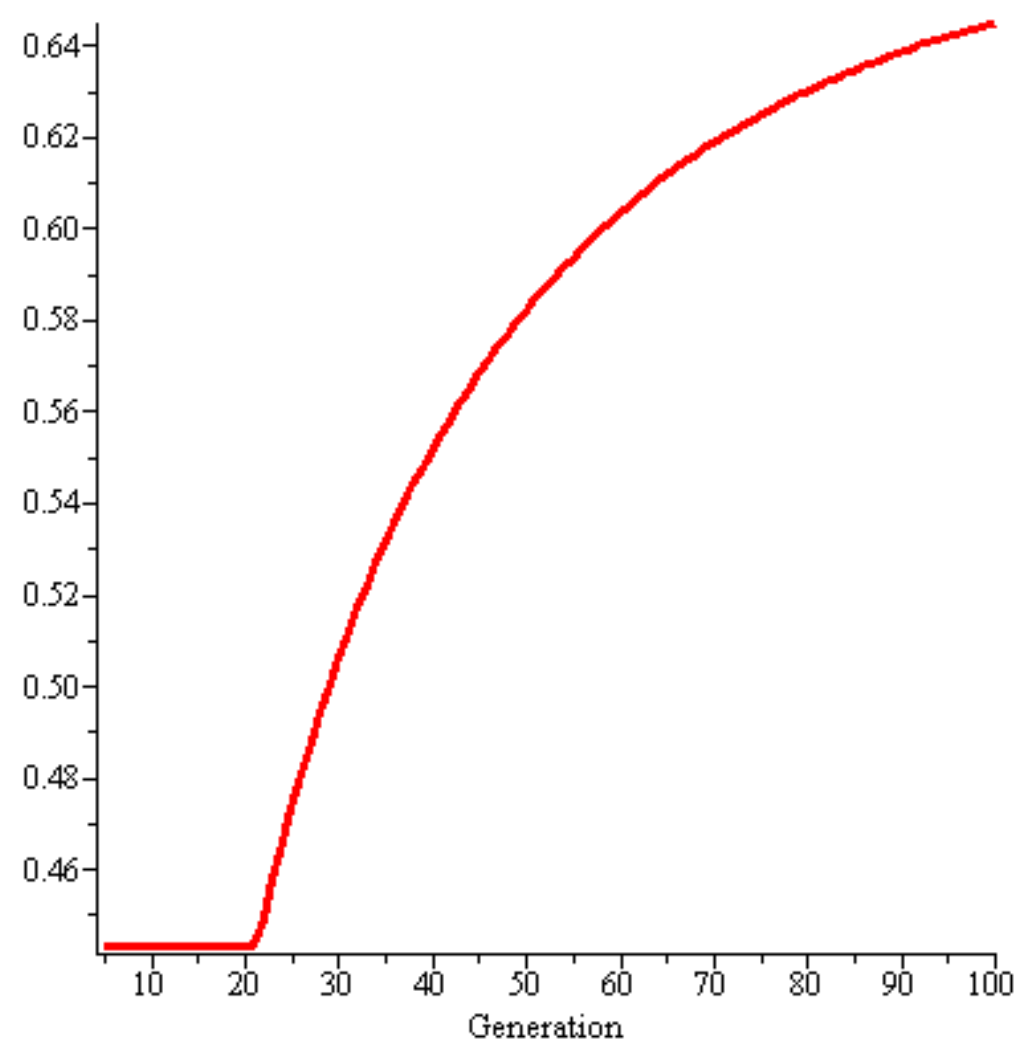

Figure 1: Urbanization $\left(\phi_{t}\right)$ 
made in order to yield reasonable initial values for the interest rate and the number of children born. Fortunately, the results are qualitatively quite robust. The figure shows a steady increase in the share of the urban population, induced by steadily increasing per capita income in conjunction with Engel's Law. As per capita income increases, a larger share of income is devoted to consumption of widgets, shifting the labor force into the cities.

Figure 2 shows the average saving rates for the urban population (upper curve), rural population (lower curve) and the economy-wide average saving rate (middle curve). The rural population displays a distinctly lower saving rate, since its fertility rate is much higher (see Figure 3 below), and children substitute for savings. Over time, however, the saving rates in both populations increase steadily, which can be explained by two forces:

- Period-1 income is increasing while period-2 income (aside from accumulated savings and transfers from children) is zero, and optimal consumption increases in both periods proportionately to income. Therefore, in order to finance the increase in period-2 consumption, saving must increase, both absolutely and relative to period- 1 income.

- Children become progressively less "profitable" because of an increase in their relative price, due to the secular increase in the wage rate (Figure 4 below). Since children substitute for savings as a source of period-2 income, the saving rate increases.

Figure 3 shows the average fertility rates for the urban and rural sectors, as well as the economy-wide average. Recall that we have assumed, for simplicity of exposition, that the "parents" are a single agent. Given this assumption, the fertility rates on the vertical axis of Figure 3 should be multiplied by 2 in order to compare them to observed fertility rates (e.g., a fertility rate of 1 corresponds to exact replacement of the current population, while in reality the corresponding fertility rate is 2 ). The overall trend is downward, despite the positive effect of the decline in the interest rate (see Figure 5 below). The decline in the fertility rate, as noted above, is a result of the secular increase in the wage rate, which increases the relative cost of raising children. 


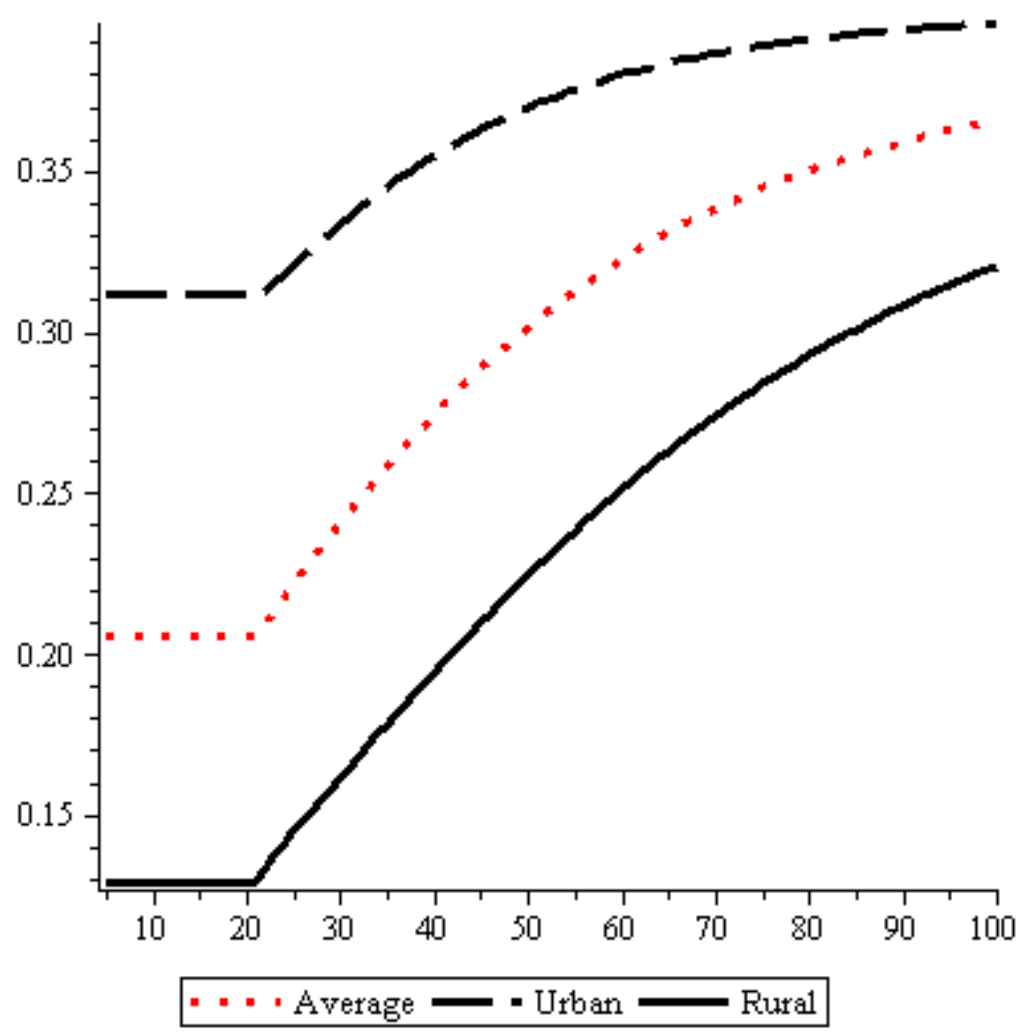

Figure 2: Saving rates 


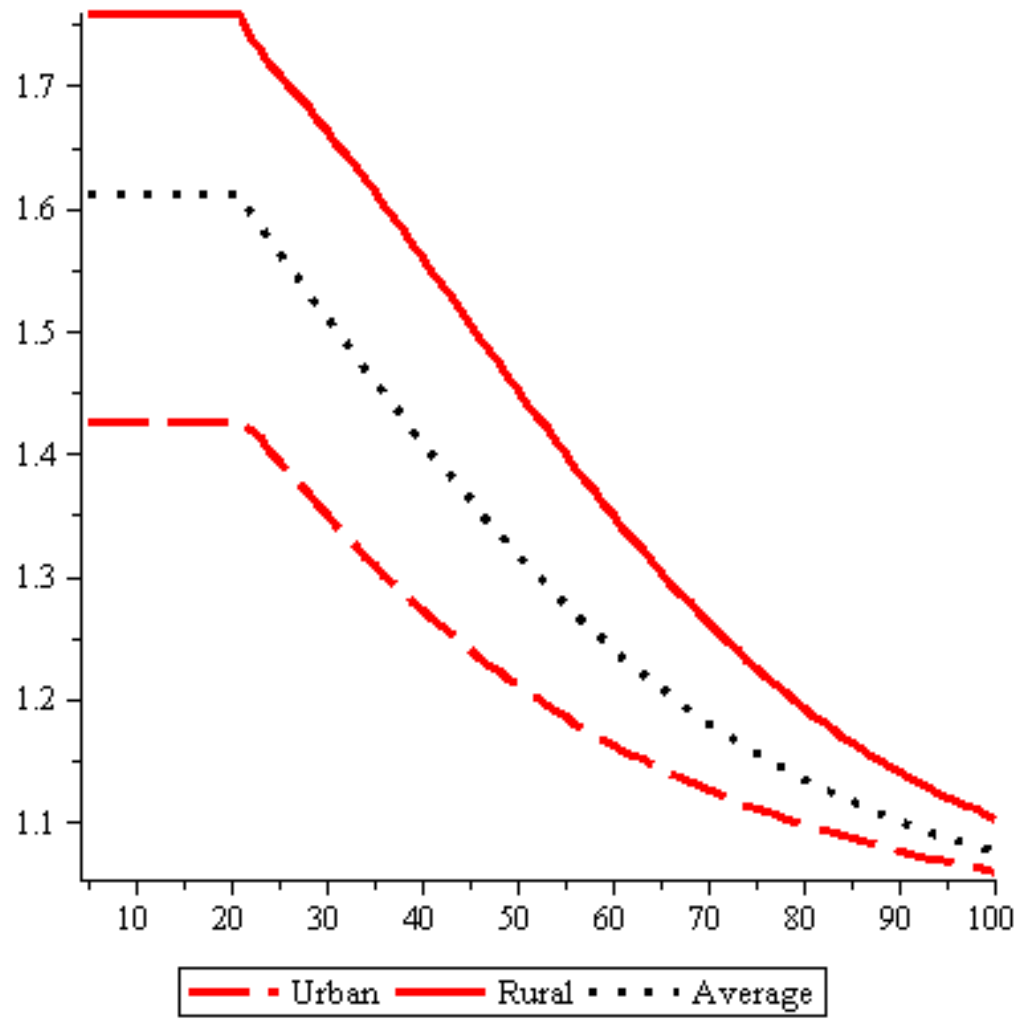

Figure 3: Fertility rates 


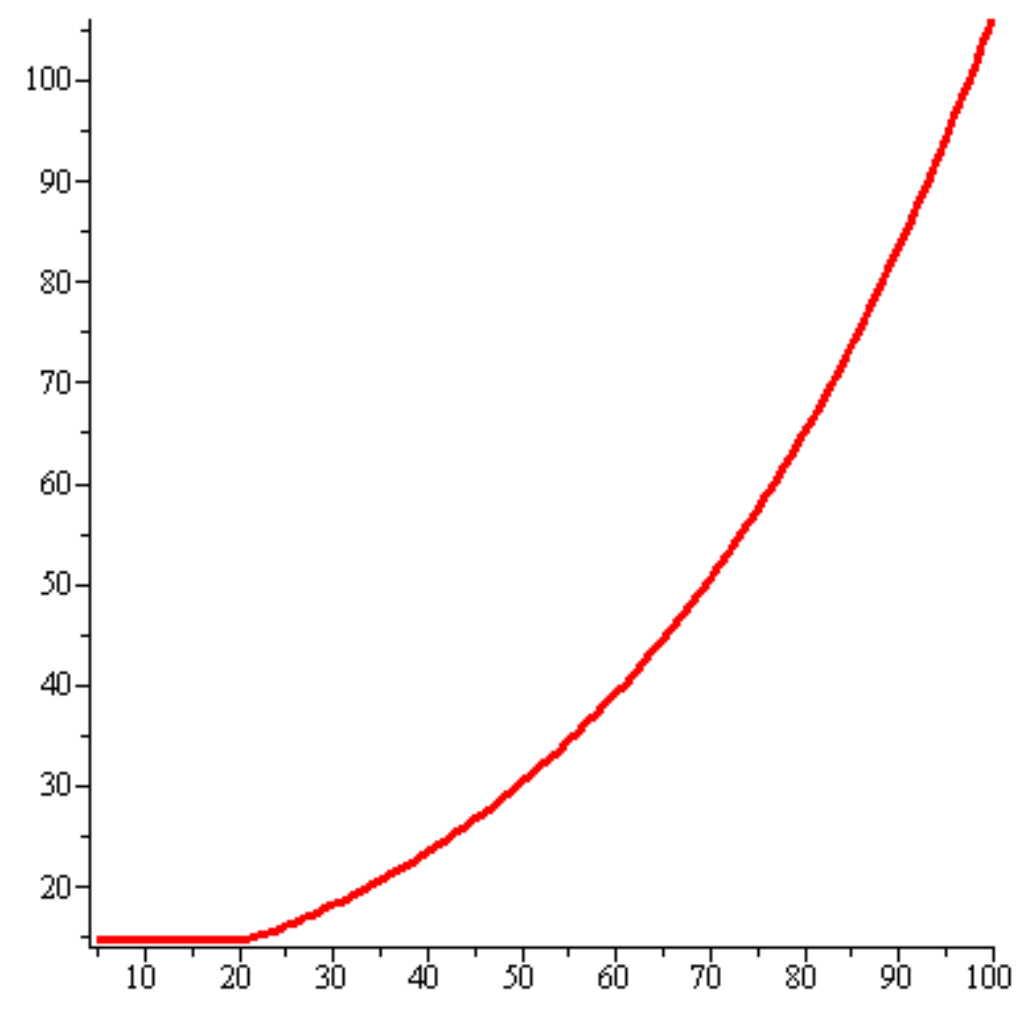

Figure 4: Wage rate

Figure 4 shows the wage rate, $w_{t}$. The increase is due both to technological change and to an increase in the capital-labor ratio. The increase in the capital-labor ratio, in turn, is caused by high and rising saving rates and declining fertility rates, as shown above. Under the assumed parameter values, the capital-labor ratio increases from 0.83 in generation 1 to approximately 18 in generation 100. (It should be recalled that 100 generations are equivalent to approximately 2,000 years.) The result of this increase in the capital-labor ratio is a steady decline in the interest rate, shown in Figure 5. (Recall that $R_{t}$ is not a per annum interest rate, but rather 1 plus the per-generation interest rate, so that an initial $R_{t}$ of 2.6 translates to only 2.4 percent per annum, assuming that a generation is 20 years.) This decline 


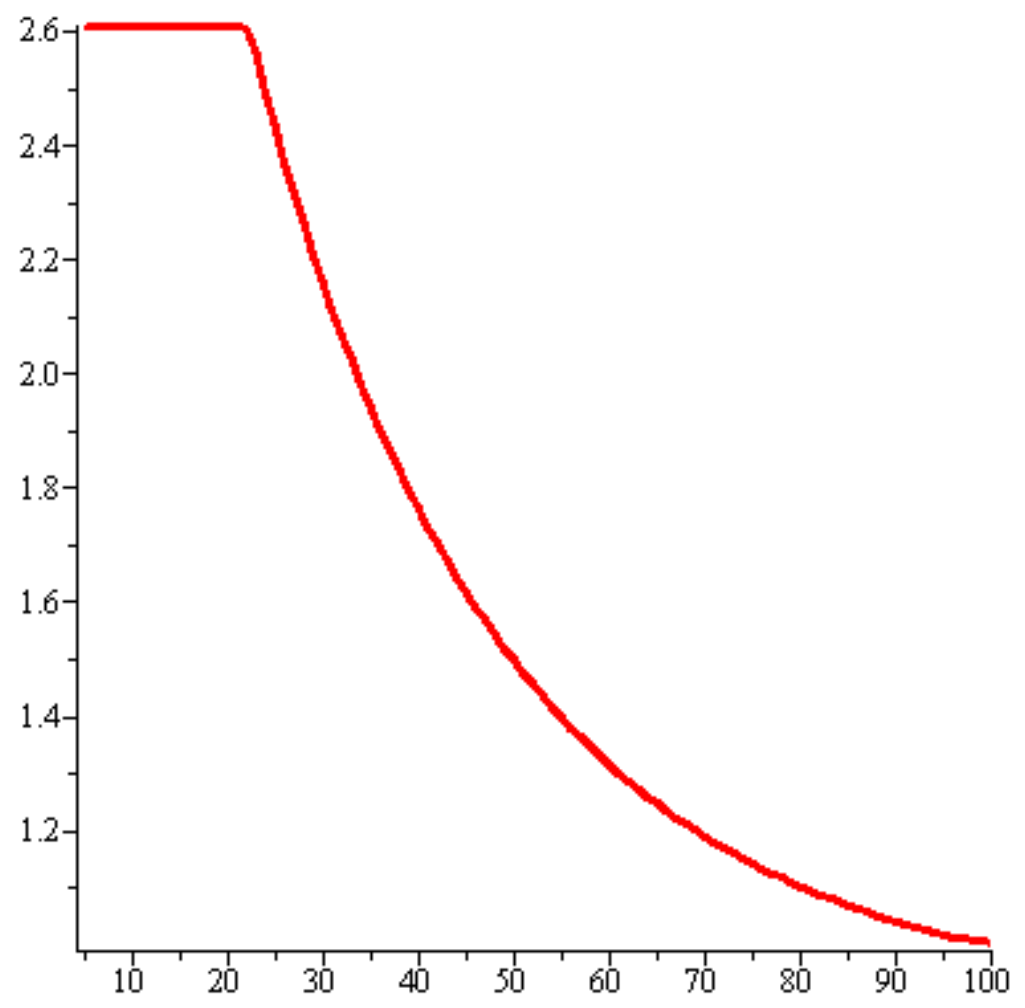

Figure 5: $R_{t}$

in the interest rate occurs despite technological change, which increases the interest rate by increasing the marginal productivity of capital.

\section{Concluding remarks}

This paper has developed a two-sector OLG model of growth, with fertility, saving, and urbanization endogenous. Children are viewed as a means of old-age support, particularly in the rural sector, as well as a good valued for its own sake. The model is based on rather standard assumptions regarding technology and preferences. While the rate of technological change is endogenous (an increasing function of urbanization) in the simulations 
presented here, the results are almost identical if exogenous technological change, at a comparable rate, is assumed. The implication is that the effect of urbanization on innovation and human capital accumulation, emphasized by the recent literature, does not appear to make a large quantitative difference. This result is in accord with recent empirical work by Henderson (2003) which calls into question the importance of the effect of urbanization on growth. Nevertheless, the model shows that urbanization is an important consequence of growth, via Engel's Law. The social effects of urbanization, including the decline of intrafamilial old-age support, are no less important than any economic effect on growth that urbanization may have.

\section{References}

[1] Alesina, Alberto; Algan, Yann; Cahuc, Pierre; and Giulano, Paola, 2010. Family values and the regulation of labor. Unpublished, Harvard University.

[2] Barro, Robert J., 1974. Are government bonds net wealth? Journal of Political Economy 82, 1095-1117.

[3] Becker, Gary S., 1974. A theory of social interactions. Journal of Political Economy 82, 1063-93.

[4] Becker, Gary S., 1981, 1991 (second edition). A Treatise on the Family. Cambridge, MA: Harvard University Press.

[5] Becker, Gary S., 1988. Family economics and macro behavior. American Economic Review 78, 1-13.

[6] Becker, Gary S., 1993. Nobel lecture: The economic way of looking at behavior. Journal of Political Economy 101, 385-409.

[7] Becker, Gary S., 1996. Accounting for Tastes. Cambridge, MA: Harvard University Press.

[8] Berg, J.; Dickhaut, J.; and McCabe, K., 1995. Trust, reciprocity, and social history. Games and Economic Behavior 10, 122-42. 
[9] Bergstrom, Theodore C. and Stark, Oded, 1993. How altruism can prevail in an evolutionary environment. American Economic Review, 83 (Papers and Proceedings), 149-55.

[10] Bian, Fuqin; Logan, John R.; and Bian, Yanjie, 1998. Intergenerational relations in urban China: Proximity, contact and help to parents. Demography 35, 115-24.

[11] Cigno, A., 1993. Intergenerational transfers without altruism: Family, market, and state. European Journal of Political Economy 9, 505-18.

[12] Cox, Donald, and Stark, Oded, 1996. Intergenerational transfers and the demonstration effect. Unpublished, Boston College.

[13] Ehrlich, Isaac, and Lui, Francis T., 1991. Intergenerational trade, longevity, and economic growth. Journal of Political Economy, 99, 1029-59.

[14] Frankenberg, Elizabeth; Lillard, Lee; and Willis, Robert J., 2002. Patterns of intergenerational transfers in Southeast Asia. Journal of Marriage and the Family 64, 627-41.

[15] Glaeser, Edward L., 1999. Learning in cities. Journal of Urban Economics 46, 254-77.

[16] Glomm, Gerhard, 1992. A model of growth and migration. Canadian Journal of Economics 25, 901-22.

[17] Güth, Werner; Schmittberger, Rolf; and Schwarze, Bernd., 1982. An experimental analysis of ultimatum bargaining. Journal of Economic Behavior and Organization 3, 367-388.

[18] Guttman, Joel M., 2000. On the evolutionary stability of preferences for reciprocity. European Journal of Political Economy 16, 31-50

[19] Guttman, Joel M., 2001a. Self-enforcing reciprocity norms and intergenerational transfers: Theory and evidence. Journal of Public Economics $81,117-51$. 
[20] Guttman, Joel M., 2001b. Families, markets, and self-enforcing reciprocity norms. Annales d' Economie et de Statistique 63-64, 89-110.

[21] Guttman, Joel M., 2003. Repeated interaction and the evolution of preferences for reciprocity. Economic Journal 113, 631-56.

[22] Hugo, G., 1992. Aging in Indonesia: A neglected area of policy concern, in D.R. Phillips (ed.) Aging in East and Southeast Asia. London: Edward Albert.

[23] Hammer, Jeffrey S., 1986. Population growth and savings in LDCs: A survey article. World Development 14, 579-91.

[24] Henderson, Vernon, 2003. The urbanization process and economic growth: The so-what question. Journal of Economic Growth 8, 47-71.

[25] Jacobs, Jane, 1969. The Economy of Cities. New York: Vintage.

[26] Jacobs, Jane, 1984. Cities and the Wealth of Nations: Principles of Economic Life. New York: Vintage.

[27] Jellal, Mohamed and Wolff, François-Charles, 2002. Cultural evolutionary altruism: Theory and evidence. European Journal of Political Economy, 18, 241-62.

[28] Kreps, David M.; Milgrom, Paul; Roberts, John; Wilson, Robert, 1982. Rational cooperation in the finitely repeated Prisoners' Dilemma. Journal of Economic Theory 27, 245-52.

[29] Lillard, Lee A. and Willis, Robert J., 1997. Motives for intergenerational transfers: Evidence from Malaysia. Demography 34, 115-34.

[30] Lucas, Robert E., Jr., 2004. Life earnings and rural-urban migration. Journal of Political Economy, 112, S29-S59.

[31] Marshall, Alfred, 1890. Principles of Economics. London: Macmillan.

[32] Mitrut, Andreea, and Wolff, François-Charles, 2009. A causal test of the demonstration effect theory. Economics Letters 103, 52-54. 
[33] Modigliani, Franco, and Brumberg, R., 1954. Utility analysis and the consumption function, in K.K. Kurihara (ed.) Post Keynesian Economics. New Brunswick, NJ: Rutgers University Press.

[34] Sato, Yasuhiro, and Yamamoto, Kazuhiro, 2005. Population concentration, urbanization, and demographic transition. Journal of Urban Economics 58, 45-61.

[35] Schultz, T. Paul, 2005. Demographic determinants of savings: Estimating and interpreting the aggregate association in Asia. Discussion paper no.1479, IZA, Bonn.

[36] Sethi, Rajiv, and Somanathan, E., 2003. Understanding reciprocity. Journal of Economic Behavior and Organization 50, 1-27.

[37] Shin, Do-Chull, 1995. Economic growth, Engel's Law, and structural transformation. Seoul Journal of Economics 8, 1-21.

[38] Shubik, Martin, 1981. Society, land, love, or money: A strategic model of how to glue the generations together. Journal of Economic Behavior and Organization 2, 359-85.

[39] Stark, Oded, 1995. Altruism and Beyond: An Economic Analysis of Transfers and Exchanges Within Families and Groups. Cambridge, UK: Cambridge University Press.

[40] Stone, Richard, 1954. Linear expenditure systems and demand analysis: An application to the pattern of British demand. Economic Journal 64, $511-27$.

[41] Zhang, Jie, 2002. Urbanization, population transition, and growth. $O x$ ford Economic Papers 54, 91-117.

[42] Zimmer, Zachary, and Kwong, Julia, 2003. Family size and support of older adults in urban and rural China: Current effects and future implications. Demography 40, 23-44. 